\title{
Las publicaciones catalanas de Buenos Aires y el impacto de la Guerra Civil española (1936-1939)
}

Alejandro Fernández

Universidad Nacional de Luján, Argentina

Fecha de recepción: 14 de abril de 2020. Fecha de aceptación: 12 de junio de 2020.

\section{Resumen}

En el artículo se analizan las opiniones de las dos principales publicaciones catalanas de Buenos Aires, las revistas Ressorgiment y Catalunya, respecto del desarrollo de la Guerra Civil española (1936-1939). También se consideran los vínculos entre estos medios de prensa y las instituciones de la comunidad catalana de la ciudad y el rol desempeñado por los primeros exiliados que llegaron al país como consecuencia de la guerra. Ambas revistas reflejaron la influencia del catalanismo en la región del Río de la Plata durante la primera mitad del siglo XX y defendieron enérgicamente los derechos históricos de Cataluña frente al avance del franquismo. Pero mientras Ressorgiment asumió como propias las posturas en favor de la secesión respecto de España y observó la guerra principalmente como un conflicto externo, Catalunya combinó una firme oposición a la rebelión militar con la apertura hacia la cooperación con la Segunda República española en la lucha antifascista. Esta diferencia habría de reflejarse también en la mayor presencia de los exiliados en la segunda revista, tanto durante la guerra como en la inmediata posguerra.

Palabras clave: Catalanismo, Guerra Civil española, Ressorgiment, Catalunya, Prensa étnica. 


\title{
Catalan publications in Buenos Aires and the impact of Spanish Civil War (1936-1939)
}

\begin{abstract}
The article analyzes the opinions of the two main Catalan publications in Buenos Aires, the magazines Ressorgiment and Catalunya, regarding the development of the Spanish Civil War (1936-1939). The links between these media and the institutions of the Catalan community in the city and the role played by the first exiles who came to the country as a consequence of the war are also considered. Both magazines reflected the influence of Catalanism in the Río de la Plata region during the first half of the 2oth century and vigorously defended the historical rights of Catalonia against the advance of Francoism. But while Ressorgiment assumed the positions in favor of secession with respect to Spain as their own and observed the war mainly as an external conflict, Catalunya combined firm opposition to the military rebellion with openness towards cooperation with the Spanish Second Republic in the anti-fascist struggle. This difference should also be reflected in the greater presence of exiles in the second magazine, both during the war and in the immediate post-war period.
\end{abstract}

Keywords: Catalanism, Spanish Civil War, Ressorgiment, Catalunya, Ethnic Media.

\section{Introducción}

Uno de los fenómenos culturales a menudo asociados con la inmigración que se estableció en Argentina y otros países receptores estuvo constituido por la edición de diarios, revistas y boletines cuyos contenidos se dirigían a las colectividades respectivas. La catalana de Buenos Aires constituye un buen ejemplo de ello, ya que, desde la aparición de L'aureneta, en 1876, y hasta un siglo más tarde, contó con una cuarentena de medios propios, cuya duración fue muy variable. Durante los últimos años, varios estudios han sido dedicados a esta prensa, en algunos casos de manera específica (Fernández, 2019b; Lucci, 2014; Villarroel, 2013; Fernández, 2010) y, en otros, como parte de exploraciones más generales (Fernández, 2019a; Irurzun, 2017; Jensen, 2010; Segura-Solé i Sabaté, 2008; Castells, 2005). En todos los casos se trataba de publicaciones que trataban de fomentar la cohesión de los catalanes que vivían en la ciudad, de promover sus actividades sociales y de reforzar los lazos de la colectividad con la tierra de origen. Además de difundir las manifestaciones culturales del catalanismo, algunas de ellas adquirieron una impronta más definidamente política, vinculada con las opciones que en ese sentido fueron surgiendo en la propia Cataluña desde comienzos del siglo XX. 
En julio de 1936, cuando se produjo el alzamiento franquista contra la República, existían en Buenos Aires dos mensuarios con esas características: Ressorgiment y Catalunya. El propósito de este artículo es realizar un abordaje comparativo de los contenidos de sus números durante la etapa de la Guerra Civil española, así como de otras cuestiones vinculadas, como los nexos de ambos con las instituciones de la colectividad, las actitudes que adoptaron ante el desarrollo del conflicto y el rol desempeñado en la prensa por los primeros exiliados catalanes llegados al país entre 1936 y 1939. Previamente realizaremos una presentación del ambiente cultural y político en el que vieron la luz Ressorgiment y Catalunya y sus posiciones en defensa del catalanismo anteriores a la guerra. La hipótesis que se tratará de sostener es que ambas publicaciones fueron radicalizando sus opiniones nacionalistas al calor del conflicto, si bien la expresión más decidida de las mismas fue casi un monopolio de la primera de las revistas mencionadas. En nuestra opinión, esta diferencia habría de gravitar también en la inmediata posguerra, ya que, mientras Catalunya mantendría una actitud más abierta respecto del conjunto del exilio -incluyendo el procedente del resto de España-, Ressorgiment insistiría en el argumento del conflicto nacional, atemperado en parte por las necesidades de la oposición común al franquismo triunfante.

\section{Prensa y catalanismo político en Buenos Aires}

La influencia de los acontecimientos políticos de la península ibérica sobre la colectividad catalana de Buenos Aires comenzó a ser relevante a partir de la guerra de Cuba y de la consiguiente crisis del Estado español, acentuándose durante el transcurso de la Primera Guerra Mundial. Sus efectos pudieron percibirse tanto en la esfera asociativa como en los medios de prensa. En cuanto a la primera, el creciente descontento de un grupo de activistas del catalanismo afiliados al Centre Català de la ciudad, hasta entonces núcleo de las actividades culturales propias y acusado por aquellos de excesivamente contemporizador frente a las convocatorias a la unidad hispánica, derivó en una escisión institucional, con la formación del Casal Català en 1908. En la nueva entidad se integraron como dirigentes algunos inmigrantes recientemente arribados desde Cataluña, con mayor conocimiento de los recientes desarrollos de la política catalana. Es así que el Casal no sólo enfatizó los contenidos culturales específicos del catalanismo en sus actividades sociales, restringiendo en ellas los aspectos recreativos y lúdicos que estaban más presentes en el Centre, sino que alternó aquellas con un mayor compromiso nacionalista en sus declaraciones públicas (Fernández, 2011). 
Un nuevo avance se produjo en agosto de 1916, al salir a la luz la revista Ressorgiment, principal expresión periodística del catalanismo de la Argentina. A través de los editoriales y artículos, en gran parte redactados por su director Hipòlit Nadal i Mallol, expresaba unas posturas radicales respecto de Cataluña y de sus relaciones con España. Este medio alcanzó una impensada longevidad, puesto que se siguió publicando hasta 1972, siempre con una frecuencia mensual que en parte podía lograrse mediante la publicación de artículos de opinión llegados desde Barcelona y otros puntos del exterior. Sus relaciones con el Casal Català fueron estrechas durante gran parte de ese lapso, pero más aun lo serían con el Comitè Llibertat, fundado en 1922 como organismo de difusión en el país del ideario y obra de Francesc Macià. El colapso de los imperios multinacionales a fines de la Primera Guerra Mundial y la independencia de Irlanda contribuyeron fuertemente a la definición de las propuestas separatistas para Cataluña (Ucelay-Da Cal, 2018) que tanto el Comité como Ressorgiment habrían de defender, cada uno en su propia esfera.

Sin embargo, los ideales independentistas no gozaban de un consenso unánime dentro de las instituciones representativas de la colectividad. Tanto el Centre Català como el más antiguo Montepío de Montserrat, dedicado al mutualismo desde 1857, eran refractarios a adoptar una definición política que pudiera asociarlos con tales posturas. Además, sus vínculos con los círculos españoles de la Argentina eran habituales y generalmente armónicos: el Centre seguía formando parte de la Asociación Patriótica Española y su teatro era en ocasiones alquilado para veladas organizadas por sus pares de otras regiones de la península, mientras que el Montepío tenía en vigencia una serie de convenios de reciprocidad con las mutuales españolas y, sobre todo, con el Hospital Español de Buenos Aires. En cambio, el Casal Català fue escenario de mayores conflictos en esa materia, que llevaron al apartamiento, a fines de la década de 1910, de algunos de sus afiliados más destacados, cuando se opusieron a que las actividades culturales de la entidad adquirieran un perfil excluyente de lo hispánico. ${ }^{1}$ Pero tampoco en el Casal el impulso separatista puede caracterizarse como hegemónico o continuo, conviviendo con una postura que reivindicaba la autonomía para Cataluña y el activismo en sus manifestaciones culturales, como el teatro, la poesía o la música, aunque menos concreta en cuanto a la cuestión de la ruptura política con España.

Paradójicamente, la difusión del nacionalismo catalán por el área rioplatense alcanzó mejores resultados durante la etapa de la dictadura del general Primo de Rivera en España. Las medidas tomadas por su régimen contra la 
Mancomunitat de Catalunya, embrión de un gobierno autonómico, y contra el uso público del catalán como lengua, tuvieron importantes repercusiones en Buenos Aires, Montevideo y otras ciudades, incluso en algunos de los núcleos generalmente moderados. Entre otros, el Centre Català trató en esas circunstancias de dar nuevo impulso a la vida cultural de su concurrido palacio, mediante actividades como las conferencias y veladas teatrales en catalán, los conciertos y los aplecs de sardanes, al tiempo que decidía editar un órgano propio de difusión, con el nombre de Catalònia, que vería la luz en diciembre de 1927. La revista, cuya frecuencia también era mensual, tenía una orientación predominantemente literaria e incluía información sobre las actividades de la entidad y de casales del interior, crónicas barcelonesas, poesías, reseñas bibliográficas y artículos sobre la geografía y la historia de Cataluña. Debido a dificultades económicas del Centre, a partir de mayo de 1930 se independizó con el nombre de Catalunya, que habría de conservar hasta su desaparición, en enero de 1965.

Mientras que Ressorgiment se financiaba hacia fines de la década a través de las cuotas pagadas por algo más de un millar de suscriptores del país y del extranjero, y con los anuncios publicados por comerciantes, empresarios y profesionales catalanes de la ciudad, Catalunya, además de este último recurso, contaba con el mecenazgo de Ferran Fontana, un industrial nacido en Barcelona y vinculado en Argentina a la explotación del tanino chaqueño, y de Ramón Girona, alto funcionario de la Compañía Hispano Americana de Electricidad (CHADE). ${ }^{2}$ Girona actuaba además como administrador de la publicación y sería su director a partir de 1936, mientras que el periodista Ramón Escarrà, una de las figuras más influyentes de la colectividad, lo hacía como secretario de redacción y editorialista, utilizando el seudónimo “Jordi d’Argent”.

Los criterios de selección de las colaboraciones recibidas eran bastante rigurosos y -hecho poco frecuente en la época- se pagaban las que provenían de autores ajenos al comité de redacción (Villarroel 2013). En los primeros años las notas de índole cultural se destacaban netamente frente a las políticas, predominando en estas últimas una línea nacionalista moderada, con variaciones a lo largo del tiempo pero mostrando diferencias con los planteos independentistas. Más allá de la común oposición a la dictadura primorriverista y sus continuadores, entre los columnistas de Catalunya

2 La CHADE fue fundada en 1920 a partir de una empresa alemana que se encargaba de abastecer de electricidad a la ciudad de Buenos Aires y alrededores. Era presidida por el economista y político Francesc Cambó y llegó a ser la principal firma entre las que, teniendo su sede central en España, actuaban en cualquier otro país del exterior. Ver Riquer, 2016. Al igual que Cambó, varios de sus principales funcionarios eran catalanes. 
había defensores del republicanismo federal, de la autonomía gradual para la región de origen y también quienes pueden ser ubicados dentro del nacionalismo radical (Fernández 2010). En sus primeros años la revista bregaba incluso por un cierto entendimiento con Madrid, insistiendo en la necesidad de que el resto de los españoles conocieran mejor la realidad de Cataluña. ${ }^{3}$ Esta mayor diversidad de opiniones, si se la compara con Ressorgiment, habría de mantenerse a lo largo de su trayectoria editorial. ${ }^{4}$

Desde luego, la caída de la monarquía y la recuperación de unas instituciones propias de gobierno fueron celebradas por ambos medios. Catalunya mantuvo una línea de constante defensa del principio autonómico y de respaldo a la Generalitat de Macià y Companys, apoyando incluso la rebelión de este último contra el gobierno español en octubre de 1934. Más enfática aún en estos puntos era Ressorgiment. En mayo de 1931 dedicó una amplia nota al banquete de adhesión al gobierno recién instalado en Barcelona, celebrado en la capital argentina y en el cual el propio director del mensuario fue uno de los principales oradores. ${ }^{5}$ Sin embargo, una decepción con la nueva realidad política surgió de la aprobación del estatuto de autonomía en 1932, al considerarlo restrictivo en varios aspectos vinculados a la soberanía, como por ejemplo en cuanto al uso público del idioma. ${ }^{6}$

Otro ámbito en el que Ressorgiment asumía un rol más militante era en lo referido a sus polémicas con los medios de prensa, incluso con aquellos de Cataluña que cuestionaban la supuesta falta de fervor patriótico de los residentes en América. En 1933, por ejemplo, el corresponsal de un diario barcelonés sostuvo que en los casales americanos reinaba la apatía, a lo cual Nadal i Mallol respondió que la descripción era certera en muchos lugares, porque los compatriotas que se afiliaban a los casales no se caracterizaban por su compromiso con la causa catalana. Pero aseguraba que parte de la responsabilidad les cabía a los integrantes de la Generalitat recuperada, ya que ellos no le habían reconocido a los compatriotas emigrados el lugar que merecían, luego de haber luchado tanto por la patria, y no apoyaban a los casales en la medida que habría cabido esperar. Agregaba que el

3 Jordi d'Argent, "La descoberta de Barcelona", en Catalunya [en adelante RC], A. III, N. 21, novembre 1929, p.2.

4 Cabe aclarar, sin embargo, que también en Ressorgiment existía una sección literaria permanente, a cargo de la poetisa Gràcia Bassa de Llorenç, quien solía incluir glosas feministas de su autoría. Sobre la figura de esta escritora ver Bacardí, 2016.

5 "Acte d'adhesió al govern provisional de Catalunya", Ressorgiment [en adelante RR], A. XVI, N. 178, maig 1931, pp.2878-2879.

6 “La marca de l'esclau, encara”, RR, A. XVIII, N. 199, febrer 1933, p.3207. 
corresponsal no debía conocer el de Buenos Aires, cuyas iniciativas y actividades lo apartaban por completo de la apatía descripta. ${ }^{7}$

Los meses previos al estallido de la Guerra Civil mostraron un reverdecer de las ilusiones políticas en ambas revistas. Las elecciones de febrero de 1936 fueron celebradas como un gran triunfo, que cerraba, según Catalunya, el ciclo nefasto iniciado en octubre de 1934 y permitía la recuperación de la Generalitat y los ayuntamientos, la liberación de los prisioneros y la renovación sustancial de las Cortes. ${ }^{8}$ En abril, su comité de redacción en pleno se sumó a la conmemoración del quinto aniversario de la proclamación de la república catalana. Ressorgiment veía corroborados sus pronósticos optimistas de que los comicios no podían ser ganados por los estrangers -denominación con la que calificaba a la CEDA y el lerrouxismo- y exhortaba a los gobernantes electos para que no actuasen por intereses partidistas, sino conformando un frente único ante el enemigo común. ${ }^{9}$ La propuesta de unidad de los patriotas catalanes reaparecería constantemente en los meses siguientes, no solamente como llamado a la resistencia frente a la temida sublevación militar, sino también contra los revolucionarios y terroristas que actuaban en la propia Barcelona y no estaban dispuestos a la obediencia a la autoridad legítima representada por la Generalitat. El asesinato en mayo del dirigente Miquel Badia a manos de un grupo armado de la Federación Anarquista Ibérica, por ejemplo, brindó ocasión para una dura condena editorial, que habría de reiterarse en numerosas ocasiones similares, con la guerra ya en marcha. ${ }^{10}$

La idea de que resultaba posible y deseable dicha unidad patriótica, excluyendo a los partidos y organizaciones que definía como españoles, es una de las más constantes en la prédica de Nadal i Mallol. Según ella, la militancia

7 H. Nadal i Mallol, “Un corresponsal mal informat”, RR, A. XVIII, N. 208, novembre 1933, p.3481. El tema reapareció en algunas ocasiones durante los años de la guerra. Cf.por ejemplo "Valoració de la Catalunya d'Amèrica" y J. Riera i Puntí, "Els catalans d'Amèrica", A. XXII, N. 207, desembre 1937, pp.4159-4160.

8 Jordi d'Argent, "'Lestatut recobrat" y “La Republica Catalana”, RC, A. VI, N. 64, març 1936, p.2.

9 "Davant la propera lluita electoral", "L'Estatut, recobrat" y "Consideracions de l'hora”, RR, A. XXI, N. 234, gener 1936, N. 236, març 1936 y N. 237, abril 1936, pp.3759, 3787 y 3803 respectivamente.

10 "Miquel Badia i Capell” y H. Nadal i Mallol, "Han mort En Miquel Badia”, RR, A. XXII, N. 238, maig 1936, pp.3823 y 3825. Badia fue uno de los integrantes de Bandera Negra, el grupo armado que llevó a cabo el frustrado complot del Garraf para asesinar a Alfonso XIII en 1925, durante su visita a Cataluña. Entre 1932 y 1934 dirigió las fuerzas policiales de la Generalitat de Catalunya, debiendo exiliarse en el último año ante el fracaso de la proclamación del Estat Català por parte del presidente Companys. 
por la soberanía nacional de Cataluña no implicaba incursionar en el campo de la política. Como sostenía en 1917, a poco de aparecer la revista: "Ya lo hemos dicho una infinidad de veces: el nacionalismo no es política” ${ }^{11}$ Es probable que, detrás de dicha actitud, se ocultase un cierto desdén por la lucha política concreta o por las vicisitudes de su práctica. El director de Ressorgiment nunca estuvo afiliado a un partido, a diferencia de lo que ocurría con su labor de periodista, en la que había acumulado experiencia en Barcelona antes de emigrar. Pero también es probable que el patriotismo "apolítico" fuese un instrumento de cierta eficacia para aglutinar en el extranjero a compatriotas cuyo compromiso con Cataluña era genérico y que no se hallaban demasiado interesados en conocer las luchas entre facciones de las etapas postreras de la Restauración y del breve período de la República.

La última manifestación pública del argumento, antes de la guerra, se produjo en ocasión del llamado "Congreso de los catalanes de Sud-América", convocado por el Comitè Llibertat y celebrado en Montevideo en junio de 1936. En el encuentro -que, pese a su nombre, contó casi exclusivamente con representantes de las comunidades rioplatenses-, Nadal i Mallol presentó una de las cuatro ponencias a debate, en la cual bregaba por una política nacional que dejara al margen los partidismos y por el reconocimiento de la Generalitat como única representante del pueblo catalán. Las demás ponencias se ocupaban de aspectos específicos que iban en la misma dirección: la formación de cámaras de comercio catalanas en América Latina, para promover la exportación de productos del país de origen, la creación de bolsas de trabajo para que los empresarios catalanes radicados en dichos países privilegiasen la contratación de compatriotas amenazados por la desocupación o la indigencia y la fundación de filiales del Comitè Llibertat, con un órgano de prensa común que defendiera sus ideales. ${ }^{12}$

\section{La patria acosada y heroica}

Las exhortaciones a la unidad se combinaron, a poco de iniciada la Guerra Civil, con otro argumento que habría de acompañarlas durante los años siguientes y seguiría resonando en la posguerra: el que sostenía que el conflicto le había sido impuesto a Cataluña por la crisis del Estado español.

11 "Associació Nacional Catalana de les Amèriques", RR, A. II, N. 12, desembre 1917, p.266 (traducción propia).

12 "Un Congrés de Catalans a Montevideo" y "1er. Congrés de Catalans a Sud-América", RR, A. XXI, N. 239, juny 1936, p.3835 y N. 240, juliol 1936, pp.3855-3857, respectivamente. 
Ramón Escarrà, tradicionalmente circunspecto en sus críticas a España, se convirtió con rapidez en uno de sus voceros. En un artículo incluido en la sección "Reflexos", que tenía a su cargo, sostenía que de las tres fronteras históricas de Cataluña -la del Pirineo, la del Mediterráneo y la de Aragón con Castilla-, la última de ellas era la que históricamente había generado las mayores tensiones a su patria, debido a las ambiciones imperialistas castellanas. Su razonamiento se apoyaba parcialmente en una reciente conferencia dictada en el Casal Català por el escritor mallorquín Joan Estelrich, a quien el estallido de la guerra había sorprendido en el extranjero y que acababa de participar en Buenos Aires en un encuentro del PEN Club Internacional. ${ }^{13}$

La visión de la guerra como conflicto interno español, en el que Cataluña se vio involucrada a su pesar, fue habitual en las páginas de Ressorgiment durante los meses iniciales. La rápida derrota del alzamiento en Barcelona, la fidelidad a la República de las fuerzas de seguridad regionales y la formación de unas milicias que se trasladaron al frente de Aragón agregaron motivos para la insistencia en la originalidad catalana. Contra las afirmaciones de que sería mejor reservar esas tropas para defender el propio territorio, se señalaba que el eterno enemigo a combatir era el ejército español, por lo que se trataba de enfrentarlo afuera, para no tener que padecerlo nuevamente. ${ }^{14}$ Cataluña, en este planteo, fue la que impidió concretar los planes del fascismo, al reaccionar con heroísmo, derrotar a los generales sublevados y llevar la lucha al exterior. Curiosamente, el relato coincidía en un punto con el de uno de los propios militares franquistas, a quien se citaba para repudiar sus declaraciones de que, luego de terminar con la supuesta revolución comunista en España, llegaría la hora de actuar contra Cataluña, considerada ésta como una suerte de país extranjero. Para el articulista, no se trataba más que de una constante histórica rastreable, al menos, desde 1714: la de un trato de sujeción externa que, al parecer, estaba llegando a su fin. ${ }^{15}$

Esta manera de ver las cosas se fue alterando desde comienzos de 1937, cuando los importantes avances del ejército insurgente en territorios hasta entonces controlados por los leales y los propios enfrentamientos internos en el bando republicano, cuyo principal epicentro se halló en Barcelona,

13 Jordi d'Argent, "Moments històrics", RC, A.VI, N. 71, octubre 1936, p.2.

14 J. Casanova, "Sota l'interrogant del temps nou", RR, A. XXI, N. 241, agost 1936, p.3876;

LI. Castelló, "Del moment” y H. Nadal i Mallol, "El nostre deure”, N. 242, setembre 1936, pp.3914-3916.

15 Fermí Fort (H. Nadal i Mallol), "Com a estrangers!", RR, A. XXI, N. 243, octubre 1936, p.3933. 
comenzaron a erosionar la convicción de que la guerra seguía diferenciando a Cataluña del resto de España. El gradual cambio de postura no fue realizado por la revista sin tener que soportar las críticas de los sectores más radicales del catalanismo, que repudiaban todo intento de acercamiento a las instituciones españolas de Buenos Aires fieles a la República. En el mes de abril, por ejemplo, esas entidades invitaron al Casal Català a participar de un acto conmemorativo del sexto aniversario de la caída de la monarquía. Luego del rechazo inicial al envite, una gestión más directa de los organizadores logró que el Casal se sumara a la iniciativa, lo cual fue respaldado por un editorial de Ressorgiment, considerando que la defensa de las instituciones democráticas y la amenaza del fascismo obligaban a realizar un alto en la lucha secular contra España. Lo significativo es que, al mes siguiente, nuevamente el editorial de primera plana estaba dedicado al problema: en respuesta a los cuestionamientos recibidos, Nadal i Mallol aclaraba que nadie debía llamarse a engaño respecto del acercamiento, puesto que, luego de concluida la horrible guerra, catalanes y españoles, así como gallegos y vascos, recuperarían sus posiciones anteriores y lucharían cada uno por sus derechos e intereses. ${ }^{16}$

Los sucesos de mayo en Barcelona y otras ciudades agregaron nuevas razones para una cierta reconciliación con la República española y con aquellos partidos de izquierda a los que seguía definiendo con tal adjetivo. Ante el importante desafío planteado por el anarquismo y la insuficiencia de las fuerzas con las que podía contar la Generalitat, esa alianza no deseada parecía convertirse en perentoria. Desde el comienzo de la guerra, Ressorgiment había observado con estupor que, por las mismas necesidades de la represión del alzamiento en Cataluña, los cuerpos del orden público que permanecieron leales (guardia de asalto, mossos d'esquadra, parte de la guardia civil) debieron ser secundados por unas milicias obreras en las que era hegemónica la influencia de la FAI y la CNT, aquellos elementos repetidamente denostados ya en vísperas del conflicto. El gobierno catalán, por lo tanto, debió atender dos frentes de manera simultánea: el de la defensa frente a los facciosos y el de la lucha contra el anarquismo. La realidad, por lo tanto, no permitía alentar el optimismo: la iniciativa política estaba en manos de fuerzas que azuzaban la lucha de clases, el parlamento catalán no daba señales de vida, la lengua había sido desplazada en los actos públicos. ${ }^{17}$ Mas la colaboración entre fuerzas catalanistas y socialistas y

16 "Explicació d'una actitud", RR, A. XXII, N. 249, abril 1937, p.4023, y "Equívocs i confusions", N. 210, maig 1937, p.4039. 
comunistas españolas había permitido marginar a los anarco-sindicalistas del gobierno, lo que constituía, según la publicación, un primer paso hacia la sensatez. ${ }^{18}$ El entendimiento que parecía surgir con el gobierno de la República establecido en Valencia, a raíz de la conferencia entre Negrín y Companys, iría en la misma dirección. ${ }^{19}$

La combinación entre guerra y violencia revolucionaria produjo la salida de los primeros exiliados catalanes hacia la Argentina, cuestión frente a la cual la actitud de ambos medios fue asimismo discrepante. Catalunya fue uno de los ámbitos de acogida y trabajo para este grupo inicial. Por ejemplo, para Joan Cuatrecasas, profesor titular de Clínica Médica en la Universidad de Barcelona, quien entró en Argentina, donde tenía parientes, en 1937, luego de un corto período en Francia. Aunque simpatizaba con la causa republicana, Cuatrecasas optó por salir de su país debido a las dificultades para seguir trabajando y a la generalización de los hechos de violencia política. ${ }^{20}$ Otro caso es el del músico Jaume Pahissa, del Conservatorio del Liceo de Barcelona, quien salió en el mismo año hacia Buenos Aires, donde dirigiría la Orquesta Municipal, además de ser un referente indiscutible de la colectividad. Las disputas internas en el bando republicano provocaron también el éxodo hacia el Plata, en 1937, del ministro de la Generalitat Rafael Closas. Más curiosa es la trayectoria de Francesc Madrid Alier, periodista y escritor que había llegado en 1936 a Buenos Aires como primer secretario de la embajada de la República y que luego se transformó en exiliado, sin haber vuelto a su país de origen. ${ }^{21}$ Los cuatro fueron colaboradores habituales del mensuario dirigido por Ramón Girona.

La apertura de Catalunya hacia el exilio temprano también se extendía a los que hubiesen debido recalar en otros países. Ya en octubre de 1936, el mensuario realizó una fervorosa convocatoria a los intelectuales, escritores y artistas, sin distinción de banderías políticas, con tal de que militasen en defensa de la lengua y la cultura catalanas, a fin de que publicaran en sus

[H. Nadal i Mallol], "Uns fets i les causes", e "Insistim!", N. 251, juny 1937, pp. 4058 y 4060.

18 "Un any de tragèdia", RC, A. XXII, N. 252, juliol 1937, p.4071. En cualquier caso, los problemas internos no concluyeron entonces, puesto que, varios meses más tarde, la Generalitat seguía careciendo de los suficientes medios como para controlar a quienes la revista consideraba como elementos terroristas. Según se argumentaba, mientras el pueblo se lanzaba a una lucha desesperada para contener a los militares sublevados, dichos elementos se dedicaban a la destrucción, la quema de iglesias y el saqueo. Cf. "Dos fets cabdals", A. XXII, N. 256, novembre 1937, p.4135.

19 "Catalunya!", RR, A. XXII, N. 254, setembre 1937, p.4103.

20 Ver el testimonio de Cuatrecasas en Schwarzstein, $2001: 86$.

21 Cf.Manent, 1989 : II, 21-22; III, 41-42, 228-229. 
páginas, si es que sobre la tierra natal se abatía "otra etapa de opresión y vilipendio”. El llamado incluía expresamente a quienes hubiesen tenido que expatriarse para salvaguardar sus vidas y sus libertades. ${ }^{22}$ Dos años y medio más tarde, en el momento en que cesaban los combates, la revista encaró una encuesta entre los notables de la colectividad de Buenos Aires, en la cual éstos coincidían en el deber de acogida de los intelectuales catalanes que llegaran desamparados. ${ }^{23}$

La postura de Ressorgiment respecto de esos primeros exiliados fue bastante más distante. Les reprochaba falta de conciencia para columbrar la revolución -implícitamente de independencia- que se aproximaba en Cataluña y en la cual ellos habrían debido desempeñar tareas muy relevantes. También censuraba el hecho de que se dejasen intimidar por los elementos incontrolados que sembraban el terror. Esa crítica, un tanto peculiar si tenemos en cuenta que provenía de una persona que llevaba ya un cuarto de siglo de residencia continua en Buenos Aires, concluía con una exhortación más general a un patriotismo que no se limitase al baile de sardanas y a la entonación de Els segadors, sino que estuviera dispuesto a expresarse en Barcelona, luchando en defensa del gobierno legítimo. ${ }^{24}$

A su llegada, los primeros exiliados pudieron advertir con beneplácito hasta qué punto la colectividad catalana de Buenos Aires -la más importante de América- contaba con unas instituciones y una prensa que seguían de cerca las vicisitudes de la guerra y que, en su mayoría, apoyaban la causa de la patria. ${ }^{25}$ Incluso en esas dramáticas circunstancias, las páginas de Catalunya y de Ressorgiment seguían conteniendo mucha información que no tenía que ver directamente con el conflicto en la península o con las campañas de ayuda para los damnificados, sino con la vida social y cultural de los catalanes de la Argentina: las veladas y representaciones que tenían lugar en el teatro del Centre o en el más modesto del Casal, los conciertos de la Escola de Música, los cursos patrocinados por la Comissió d'Educació i Ensenyament, las asambleas anuales del Montepío, el programa de audiciones de música clásica de "L'Hora Catalana", las comidas de confraternidad en la quinta "La Torre", de Vicente López, las colectas caritativas para las familias de compatriotas pobres encabezadas por la Lliga

22 Jordi d'Argent, "Un refugi de la cultura catalana”, RC, A. VI, N. 71, octubre 1936, pp.7-8. 23 “Enquesta”, RC, A. X, N. 100, març 1939, pp.8-9 y 32.

24 Fidel Català [H. Nadal i Mallol], "Consciència revolucionària”, RR, A. XXII, N. 248, març 1937, pp.4007-4008; “Els deures del patriotisme”, N. 257, desembre 1937, p. 4151.

25 Cf. por ejemplo las palabras de Cuatrecasas en "Sopar en honor d'Irene Polo, Francesc Madrid i Dr. Joan Cuatrecasas", RC, A. VIII, N. 77, abril 1937, p.30. 
de la Mare de Deu de Montserrat, las exposiciones de pintura y escultura de los numerosos artistas catalanes que vivían en el país o las diferentes actividades de los casales del interior. También dedicaban páginas enteras a acontecimientos que para la comunidad adquirían especial relevancia, como la visita a Buenos Aires de Pau Casals en agosto de 1937.

\section{El naufragio de las esperanzas}

El contraste entre el bienestar que reflejaban esas notas dedicadas a un catalanismo floreciente en el Río de la Plata y las crecientes penurias vividas en la tierra de origen se volvía cada vez más elocuente, aún cuando ambas revistas trataban de destacar la continuidad de una cierta vida cultural en Barcelona o Gerona o los signos que permitían alentar el optimismo sobre la situación del frente de batalla o sobre las posibles consecuencias de la guerra. Escarrà, por ejemplo, abundaba en efusiones de orgullo por el hecho de que Cataluña se estuviera convirtiendo en el principal sostén del ejército republicano y sus jefes militares en interlocutores frecuentes del estado mayor del general Miaja. ${ }^{26}$ Más adelante agregó otros motivos, como el hecho de que la Generalitat por primera vez contaría con facultades para emitir dinero con la imagen de las cuatro barras o el acuerdo sobre la co-oficialidad del catalán como lengua, otorgado por el gobierno de la República, al trasladarse desde Valencia. ${ }^{27}$

Catalunya fue reflejando en sus páginas los cambios que la guerra introdujo en la vida cotidiana de Barcelona y otras ciudades, como por ejemplo los festivales musicales a beneficio de las milicias, las manifestaciones en las que destacaba la presencia de militantes munidos de "banderes catalanes amb l'estel solitari" -símbolo independentista-, las discusiones políticas en los cafés y la radical modificación de los comensales del lujoso hotel Ritz, incautado por las organizaciones obreras. ${ }^{28}$ Uno de los corresponsables de Ressorgiment, por su parte, se lamentaba de la falta de patriotismo con la

26 Jordi d'Argent, "Any Nou” y "Germanor i beneficència", RC, A. VII, Nº 74, gener 1937, pp.2-3; "El comandament", RC, A. VII, N. 76, març 1937, p.2.

27 Jordi d'Argent, "Moneda catalana", RC, A. VII, N. 77, abril 1937; "El respecte a l'idioma"; A. IX, N. 86, gener 1938, pp.2-3. Escarrà agregaba en el segundo de esos editoriales que la co-oficialidad del idioma ni siquiera se había logrado en el estatuto de autonomía de 1932, lo que demostraba el nuevo respeto que la República tenía por Cataluña y la enorme diferencia de trato que cabía augurar si se daba la remota posibilidad de que la guerra concluyera con el triunfo de Franco.

28 "El Ritz sotragat per la guerra" y "Actualitat catalana", RC, A.VI, N. 71, octubre 1936, pp.16-17 y 19; "La vida a Barcelona”, A. VII, N. 81, agost 1937, pp.23 y 28. 
que había sido conmemorado el 11 de setiembre en 1937, analizando las duras circunstancias que atravesaba la ciudad de Barcelona, bombardeada con frecuencia y teniendo que albergar a miles de refugiados, el peligro que representaban los agentes secretos del franquismo y el gran aumento en el costo de vida. ${ }^{29}$ También se transmitían informaciones sobre la forma en que las tropas franquistas estaban tratando a los catalanes en las zonas capturadas, para que nadie se hiciera ilusiones, a partir de prejuicios sociales o religiosos, acerca de lo que podría ocurrir con el triunfo de los insurgentes. ${ }^{30}$

La principal intervención de la colectividad catalana de Buenos Aires en la Guerra Civil española no debe hallarse, sin embargo, en la prédica política o humanitaria que pudiera emanar de sus instituciones y medios periodísticos, sino en el nivel más concreto de la ayuda para los damnificados. Ya en setiembre de 1936, la junta directiva del Casal Català fijó un impuesto sobre las entradas de su teatro y organizó una colecta entre sus afiliados con ese propósito. A continuación, tanto el Casal como el Comité Llibertat iniciaron una serie de envíos de alimentos, medicinas y ropas, cuyo primer embarque se llevó a cabo tres meses más tarde. ${ }^{31}$ Este tipo de acciones continuó durante todo el conflicto, a veces en coordinación con otras entidades, como el Centro Republicano Español, la Acción Nacionalista Vasca, la Asociación Protectora Balear, los casales del interior y la embajada española. ${ }^{32}$ Durante la etapa en que el sistema alcanzó su mayor desarrollo, en la segunda mitad de 1937 y a lo largo de 1938, se integraban en los embarques las provisiones que las familias catalanas residentes en el país enviaran a sus parientes o bien a aquellos que, sin serlo, habían sido apadrinados a tal efecto. ${ }^{33}$

Otra importante iniciativa del Casal consistió en financiar una de las escuelas para niños vascos refugiados en la localidad de Torrentbó, que mantuvo su actividad hasta comienzos de 1939, mientras que el Centre Català llegó a sostener otra para unas decenas de huérfanos catalanes en la Costa Brava. ${ }^{34}$ Menos suceso alcanzó, en cambio, una campaña para la adopción

29 X. Desplà, "Al llindar de la meva porta", RR, A. XXII, N. 255, octubre 1937, pp.4121-4122.

30 "Com tracten els catalans la gent de Franco", RR, A. XXII, N. 256, novembre 1937, pp. $4135-4136$.

31 "Ajut als nostres germans!", RR, A. XXI, N. 245, desembre 1936, p.3969.

32 Abundante información sobre estas actividades pueden verse en Archivo del Casal Català (ACC), Llibre d'actes d'assemblea, 1930-1940, ff.406-461; Llibre d'actes de comissió directiva, 1938-1940, passim.

33 “Crida urgent”, RR, A. XXII, N. 255, octubre 1937, p.4119; "Padrinatge de guerra”, RR, A. XXIII, N. 266, setembre 1938, p.4306. 
de huérfanos, ya que su traslado al país resultó casi imposible de concretar. Tampoco tuvo efectos prácticos, debido a la propia dinámica de la guerra en sus tramos finales, la decisión del Comité Llibertat de sostener una colonia infantil en la comarca del Montseny, para niños desplazados por el avance del enemigo en Lérida y Tarragona. ${ }^{35}$ En cualquier caso, estas acciones eran muy publicitadas por las revistas, especialmente por Ressorgiment, que veía en ellas el indicio más auspicioso de la vitalidad del patriotismo.

No obstante, se trataba de emprendimientos que tampoco lograban un consenso unánime dentro de la colectividad. El Centre Català sólo se sumó a ellas en algunas ocasiones, cuando la situación en Barcelona se había vuelto más apremiante, mientras que el Montepío de Montserrat apeló a lo establecido por sus estatutos sociales para mantenerse al margen. Incluso en el Casal Català surgieron desavenencias y conflictos por la organización de la ayuda. Su presidente, el ingeniero Ramón de Fortuny, que había logrado la reelección debido al exitoso rescate de la crisis financiera que atravesaba la entidad, fue cuestionado por los nacionalistas más radicales -varios de los cuales eran a la vez dirigentes del Comité Llibertat- por su supuesta actitud de excesiva cooperación con Ossorio y Gallardo, embajador de la República española. Luego de recurrentes discusiones en las asambleas, Fortuny presentó su renuncia en julio de 1938, pese a la defensa de su accionar que intentó un sector de los afiliados más antiguos. ${ }^{36}$

Las novedades del frente militar fueron ocupando un espacio cada vez más reducido en las páginas, en parte porque se trataba de informaciones ya conocidas, a través de los grandes medios de prensa de la ciudad, pero sobre todo porque sólo suponían decepción y presentimientos de derrota final. La captura de Teruel por el ejército republicano generó una última oleada de optimismo, permitiendo que Nadal i Mallol arremetiera con duras palabras dirigidas a los derrotistas que, según él, abundaban entre

de Catalunya!", RR, A. XXIII, N. 264, juliol 1938, p.4264; "Entitats Catalanes de l'Argentina”, RC, A. IX, N. 90, maig 1938, A. p.29; "Una visita a Torrentbó”, RR, A. XXIII, N. 267, octubre 1938, p.4317.

35 “Colonia infantil Comité Llibertat”, RR, A. XXIII, N. 268, novembre 1938, p.4335.

36 El detalle de las discusiones puede verse en ACC, Llibre d'actes d'assemblea, op.cit., sessions del 28 febrer 1937, 18 juliol 1937, 13 febrer 1938, 31 juliol 1938. Ya al repasar la historia del Casal, en ocasión de su $30^{\circ}$ aniversario, Nadal i Mallol concluía que la situación presente se caracterizaba por la pérdida del pulso patriótico. Las razones, a su juicio, eran varias: la prolongación de la guerra más allá de lo que cabía vaticinar, la presión de las entidades republicanas españolas que tendían a alejar al Casal de su esencia o la incomprensión respecto de la política encarada por la Generalitat. Cf. "En el trentè aniversari del Casal Català. Historia abreujada de la seva existència”, RR, A. XXIII, N. 260, març 1938, pp.4203-4204; “En el Casal Català”, N. 262, maig 1938, pp.4241-4242. 
los catalanes de la Argentina. ${ }^{37}$ El triunfo fue sobredimensionado también por Escarrà, quien planteó que la guerra presentaba dos fases, antes y después de Teruel, ya que allí se había visto un ejército republicano finalmente bien organizado, armado, dirigido y con eficacia combativa, capaz de apoderarse del "vértice milenario de Iberia", entre las tierras catalanas y castellanas. Dado que, aun contando con la ayuda de las potencias totalitarias de Europa, Franco no había sido capaz de concluir la guerra en el año y medio transcurrido, los militares leales habían conseguido superar un grave desafío, pendiente desde el comienzo de la conflagración. Ello demostraba las virtudes del entendimiento alcanzado entre la Generalitat y el gobierno de la República. ${ }^{38}$ La sobreestimación de la importancia estratégica de Teruel hizo que su rápida reconquista por parte de los insurgentes tuviera un efecto letal sobre la campaña de ambas publicaciones, en las que prácticamente va a desaparecer desde entonces el tema de las operaciones bélicas.

Otro tema vivido con creciente frustración fue el de la anhelada intervención de las democracias occidentales en el conflicto o, al menos, el de la imposición estricta de la no injerencia que en teoría sostenían. Hasta mayo de 1938 el cuerpo de redactores de Catalunya conservó unas vagas ilusiones acerca de lo que en ese sentido podía gestionar Inglaterra en la Sociedad de Naciones, pero las deliberaciones de ese mes en Ginebra, en las que una dictadura pro-Eje como la rumana había contado con un voto decisivo en el escrutinio sobre España y Abisinia, terminó por derrumbarla. ${ }^{39}$ Las esperanzas de Nadal i Mallol resultan aún más ingenuas, al menos con una visión retrospectiva, ya que hasta fines del año anterior creía de buena fe que el derrumbe del frente del norte de España podía derivar en una suerte de arbitraje internacional para consagrar el equilibrio de los dos bandos en guerra, de resultas del cual hasta podía presentarse la oportunidad de conformar una república catalana independiente. ${ }^{40}$ La siguiente opción que sugirió, ya con las tropas de Franco trasladadas desde Asturias

37 "Guanyar o perdre", A. XXIII, N. 258, gener 1938, pp.4172-4173.

38 Jordi d'Argent, "El vèrtex de Terol", RC, A. IX, N. 86, gener 1938, p.2.

39 J. d’Argent, "La Lliga Antinacions", RC, A. IX, N. 90, maig 1938, p.2.

40 P. de Reig [H. Nadal i Mallol], "Quán es decidirà Anglaterra”, RR, A. XXII, N. 256, novembre 1937, p.4144. La utopía independentista afloró en anteriores ocasiones durante la guerra (cf. por ejemplo Nadal i Mallol, H., "Aspectes de la Revolució", RR, A. XXI, N. 244, novembre 1936, p.3950) e incluso en vísperas de su estallido. Ressorgiment se hizo eco entonces de un rumor, carente de sustento pero recogido por la prensa porteña, sobre la posilidad de que la Generalitat declarara la secesión de Cataluña en caso de que en Madrid se estableciera una dictadura proletaria encabezada por Largo Caballero. Cf. "Una informació sensacional”, RR, A. XXI, N. 240, juliol 1936, p.3851. 
hacia Aragón, fue la no menos inverosímil anexión de Cataluña a Francia, si bien en este caso para repudiarla, con el argumento que los catalanes transpirenaicos apenas conservaban algunos de sus rasgos culturales y no tenían objetivos políticos propios debido a que formaban parte de un Estado moderno, democrático e integrador. La conclusión, por tanto, era que, en caso de anexión a Francia, también la Cataluña del sur abandonaría su rica historia de oposición al centralismo castellano y acabaría diluyéndose como nación. ${ }^{41}$

El balance final del conflicto esbozado por Ressorgiment recuperaba la idea de la originalidad de Cataluña entre las nacionalidades ibéricas. No solamente habría evitado que la República española sucumbiese al primer golpe, al reprimir el alzamiento en su propio territorio, sino que se habría hecho cargo de otros frentes, como el de Aragón o el de Mallorca, en los que la falta de armamento o la impericia de la conducción militar española habrían impedido la concreción de sendas victorias esenciales. Cataluña, por otro lado, no habría contado en 1936 con industrias de guerra ni academias militares debido a la antigua sospecha de los diferentes gobiernos, monárquicos o republicanos, de que podría emplearlos para sus propósitos separatistas. Fue por ende necesario crear las industrias y las academias, pero los armamentos que se producían y el heroísmo de los soldados eran insuficientes frente a la inmensa ayuda que los totalitarismos brindaban a Franco. En esas condiciones se llegó al ataque sobre Barcelona, que cayó con rapidez porque estaba extenuada: por los miles de hombres que había enviado a Madrid, por el épico ataque en el frente del Ebro, por la tentativa de salvar a Valencia, por el agotamiento de su esfuerzo productivo. Pero también por factores políticos, como la dudosa actuación de figuras de la República que decidieron hacer de Cataluña la víctima propiciatoria. La lección a extraer para el futuro, según la revista, era la de que, mientras los catalanes estuviesen sujetos a otro Estado, sería éste el que se quedara con el mérito y las glorias de la victoria, mientras que los fracasos les serían adjudicados en exclusividad. ${ }^{42}$

\section{Conclusiones}

La Guerra Civil española marcó un punto muy alto en la prédica nacionalista de Ressorgiment y Catalunya, revistas surgidas en el seno de la colectividad residente en Buenos Aires pero cuyo alcance comprendía también

41 H. Nadal i Mallol, "Catalunya, francesa?”, RR, A. XXIII, N. 261, abril 1938, p.4222-4223.

42 N-M. [H. Nadal i Mallol], “Consideracions”, RR, A. XXIV, N. 271, febrer 1939, p.43794380. 
a las del interior e incluso a algunas de las radicadas en otros países de América Latina. El fracaso inicial del alzamiento en Barcelona, las vicisitudes del frente de Aragón, los conflictos internos de las fuerzas leales a la República, los bombardeos de las ciudades, las crecientes penurias de su población, los acuerdos y desavenencias entre la Generalitat y los gobiernos sucesivamente instalados en Madrid y Valencia y el avance final del ejército insurgente hacia el norte del Ebro se reflejaron ampliamente en las páginas de unos mensuarios que, desde su origen, habían hecho de la información procedente de Cataluña la materia prima con la que elaboraban sus notas y editoriales.

La oposición al franquismo gozaba de amplio consenso entre los lectores de ambas publicaciones y, más en general, entre los catalanes de la ciudad que participaban de la vida social de la comunidad. La autonomía obtenida con el estatuto de 1932, el cese de las restricciones vinculadas con el uso de la lengua propia y el funcionamiento de instituciones políticas como la Generalitat y el Parlament, habían generado una fuerte afinidad con la República española, aun cuando los núcleos nacionalistas radicales, que expresaba principalmente Ressorgiment, mantuvieran siempre viva la esperanza de la secesión de Cataluña o, al menos, de la constitución de una federación de nacionalidades ibéricas. Por consiguiente, la posibilidad de la derrota, más allá de las dolorosas consecuencias que seguramente acarrearía en otros planos, era asociada con la pérdida de las libertades y la sujeción al centralismo español.

La exaltación del sacrificio llevado a cabo por el pueblo catalán durante la guerra fue un tema frecuente y compartido por las dos redacciones. Para Catalunya constituía un motivo de orgullo y distinción, en cuanto diferenciaba a aquél de otros pueblos ibéricos, menos tenaces o exitosos en su resistencia ante el fascismo. Sin embargo, la apelación a la lucha antifascista, que encontraría codo con codo a españoles y catalanes, era una parte esencial del relato de la revista. Sin dejar de recurrir por completo a esta demanda, Ressorgiment ponía mucho más el énfasis en la naturaleza opresiva del Estado español y en el recuento de las responsabilidades que a los gobiernos de la República les habrían cabido en una derrota que podía haberse evitado. Por otro lado, insistía en que las causas del conflicto eran esencialmente externas, es decir debían buscarse en los males seculares de España, como el militarismo o el clericalismo, frente a lo cual a Cataluña sólo podía oponer la resistencia y, eventualmente, la separación. Las condiciones en que se vivía la guerra en Buenos Aires, contando con información fragmentada y a menudo tendenciosa o interesada, contribuyen a explicar las fantasiosas proyecciones que mantuvo la revista prácticamente hasta la caída de Barcelona. 
La actitud asumida frente a la llegada al país de la primera camada de exiliados también implicó una discrepancia entre ambas revistas. Mientras Catalunya los recibió con beneplácito y sumó a varios de ellos a su elenco de colaboradores habituales, Ressorgiment asumió una postura más reticente, objetando una supuesta debilidad en la confrontación con las agrupaciones no nacionalistas que participaban en el gobierno de la Generalitat y, más en general, en la resistencia al alzamiento. Ese conjunto inicial estaba constituido por individuos receptivos a la prédica catalanista y, en algunos casos, ellos mismos habían sido sus voceros. Por lo tanto, coincidían, en grandes líneas, con el tipo de argumentos que planteaba la prensa de la colectividad residente en Buenos Aires, lo cual favoreció dicha integración. Algo similar había ocurrido con los expatriados que arribaron en anteriores situaciones desfavorables en la península, especialmente durante los años de la dictadura de Primo de Rivera. Es por ello que, para quienes más insistían en la necesidad de revertir, en medio del drama de la guerra, la desfavorable distribución de las fuerzas antifascistas en Cataluña, esas salidas hacia América fuesen consideradas como deserciones irreparables. 


\section{O Bibliografía}

» Bacardí, M. (2016). Gràcia Bassa, poeta, periodista i traductora. Ajuntament de Palafrugell.

»Castells, V. (2005). Nacionalisme català à l'exili. Rafael Dalmau editor.

»Dedeu, M. (1919), El catalanismo en acción. Fijando posiciones. Librería “La Facultad".

»Fernández, A. (2010). La revista Catalunya de Buenos Aires, el exilio y la colectividad inmigrada (1927-1964). Estudios Migratorios Latinoamericanos, 24 (69), 389-412.

»Fernández, A. (2011). Prèdiques de germanor. Las asociaciones catalanas de Buenos Aires y sus prácticas institucionales (1850-1940). Historia Social, 70, 63-80.

»Fernández, A. (2019a). Los catalanes y Buenos Aires. Inmigración, asociaciones y prensa. Almaluz-Diputació de Girona-Casal de Catalunya.

»Fernández, A. (2019b). La revista Ressorgiment y la colectividad catalana de Buenos Aires (1916-1946). Revista Internacional de Historia de la Comunicación, 12, 155-177 http://dx.doi.org/10.12795/RiHC.2019.i12.08

»Irurzun, J. (2017). Redes de sociabilidad artística y cultural. El activismo de los catalanes de Buenos Aires (Argentina, inicios del siglo XX). En A. Reguera (Dir.), Vínculos que configuran redes. Las dimensiones relacionales de lo social y sus articulaciones a escalas diferenciadas (pp.219-244). Buenos Aires: Teseo.

» Jensen, S. (2010). La comunidad catalana en Argentina al arribo de los exiliados de 1939: tensiones y debates en el mantenimiento de la unidad nacional. Estudios Migratorios Latinoamericanos, 24 (69), 413-436.

"Lucci, M. (2014). La revista Ressorgiment en la historia catalana: un proyecto editorial para la difusión del catalanismo político. Buenos Aires: 1916-1936. Estudios de Historia de España, XIV, 255-279.

»Manent, A. (dir.) (1989). Diccionari dels catalans d'Amèrica. Contribució a un inventari biográfic, toponímic i temàtic. 4 vols. Generalitat de Catalunya.

» Riquer, B. de (2016), Cambó en Argentina. Negocios y corrupción política. Edhasa.

»Schwarsztein, D. (2001). Entre Franco y Perón. Memoria e identidad del exilio republicano español en Argentina. Crítica.

» Segura, A. y Solé i Sabaté, J.M. (Dirs.) (2008). Catalunya al món. La presència catalana al món, segles XIX i XX. Generalitat de Catalunya.

»Ucelay-Da Cal, E. (2018). Breve historia del separatismo catalán. Edicions B.

»Villarroel, J. C. (2013). Exilio e integración. Ressorgiment. En E. Sarmiento y R. Farías (Orgs.), Novos olhares sobre a imigraçao ibérica em América Latina (séculos XIX e XX) (pp.178-202). Universo. 